\title{
Biogeochemical response of an intact coastal sediment to organic matter input: a multivariate approach
}

\author{
Ida-Maja Karle ${ }^{1}$, Per O. J. Hall ${ }^{1}$, Ingela Dahllöf ${ }^{2, *}$ \\ ${ }^{1}$ Department of Chemistry, Göteborg University, Kemivägen 10, 41296 Gothenburg, Sweden \\ ${ }^{2}$ Department of Marine Ecology, National Environmental Research Institute, Frederiksborgvej 399, 4000 Roskilde, Denmark
}

\begin{abstract}
We tested the effect of additions of organic matter of different quality (C:N ratio) and quantity on benthic fluxes of ammonium, nitrate, silicate, oxygen and dissolved inorganic carbon (DIC). Additions were made to intact sediment boxes, according to a 2-level factorial design, and the magnitude and temporal scale of the response were evaluated with Partial Least Square (PLS) regression analysis. Response patterns were followed over a $40 \mathrm{~d}$ period following the addition, but only fluxes of ammonium, nitrate, silicate and oxygen for the first $2 \mathrm{~d}$ after addition, and nitrate fluxes for the first $8 \mathrm{~d}$ after addition, could be used for predictive modelling. The results showed that the response of the microbial community to different qualities and quantities of organic matter may initially be related to its capacity to sequester organic matter, and in the long term, to its growth in response to the respective nutritional supply. The results also suggest that such an experimental approach can be a useful tool for classification of areas with potential risk of eutrophication.
\end{abstract}

KEY WORDS: Benthic flux $\cdot$ Organic matter $\cdot$ Eutrophication $\cdot$ Sediment $\cdot$ Multivariate analysis

\section{INTRODUCTION}

Coastal marine sediments play an important role in the recycling of nutrients through degradation of organic matter originating from marine primary production and run-off from terrestrial sources. The increased use of fertilizers in agriculture over the last 50 yr has increased the anthropogenic component of nutrient run-off (Galloway et al. 2004), and has had severe effects on many coastal areas, such as oxygen depletion and temporary elimination of fauna (Rosenberg \& Nilsson 2005). Such effects are easily detected without sophisticated analytical investigations; for example, the smell of hydrogen sulfide, and the absence of macro- and meiofauna are immediately evident. However, before reaching such a state, the sediment ecosystem undergoes a gradual change (Pearson \& Rosenberg 1978), as oxygen demand increases parallel to the increased input of organic matter, resulting in increasingly more reduced sediment. Changes in benthic fluxes of nutrients and metals at the sediment-water interface are a measurable response to inputs of organic matter (Aller \& Benninger 1981, Enoksson \& Rudén-Berg 1983, Sundby et al. 1986). Such changes are determined by a series of measurements over a certain period of time of the relevant solute in the overlying water. When carried out as incubations of intact sediment ecosystems, either in situ or under in situ-like conditions in a laboratory, benthic flux measurements are complex and variable, and are thus frequently performed as incubations of sieved sediment, often with a set number of individuals of different macro- and/or meiofaunal species in each replicate (Hansen \& Blackburn 1991, Van Duyl et al. 1992, Sloth et al. 1995, Hylland et al. 1996, Pedersen et al. 1999, Bianchi et al. 2000). Studies on sieved sediments reduce the natural heterogeneity and complexity of the sediment ecosystem, thereby reducing variability, and thus enable optimal replication and presumably less complexity in data interpretation. The major drawback of such simplified experimental systems is loss of ecological relevance in 
heavily manipulated sediments. Furthermore, in many studies examining response of sediments to additions of organic matter, the additions are often relatively large, typically in the range of 1 to $4 \mathrm{~mol}$ organic carbon (OC) $\mathrm{m}^{-2}$. This corresponds to 4 to 8 times the estimated natural spring bloom sedimentation of the Baltic of 0.48 to $0.96 \mathrm{~mol} \mathrm{OC} \mathrm{m}^{-2}$ (Bianchi et al. 2000), or 2 to $12 \%$ of the annual supply of OC defined as eutrophic conditions (Nixon 1995). Nevertheless, large organic additions are of interest for studies on eutrophicated areas, or areas at potential risk of eutrophication, as large additions give a clear response. Studies on the response of intact sediment to small additions are few. Enoksson (1993) added $76 \mathrm{mmol} \mathrm{N} \mathrm{m}^{-2}$, which according to the Redfield ratio corresponds to $0.50 \mathrm{~mol} \mathrm{C} \mathrm{m}^{-2}$. The purpose of such studies are more descriptive (e.g. to examine the pathways of recycling of organic matter) rather than predictive (e.g. determine the sediment response to organic matter additions of different size and quality). Recent reviews of eutrophication in the coastal marine environment (Grall \& Chauvaud 2002, Gray et al. 2002) emphasised the importance of detection and quantification of eutrophication effects at its early stages. It would therefore be advantageous if changes in fluxes at natural levels of organic matter input were determined under conditions more comparable to those in situ. Thus, such an approach should include high variability and complexity. In this study we used a multivariate approach enabling simultaneous evaluation of several variables that are not necessarily independent. Multivariate methods can also reveal hidden relationships between samples and the relative importance of the variables analyzed (Morgan 1991, Wold 1995). Such investigations focusing on the dynamics of sediment responses to small organic additions reflect the normal behaviour of a sediment ecosystem. They can be used to improve existing models (Wulff et al. 2001) of the coastal marine environment.

The aim of this study was to evaluate if the sediment response to ecologically relevant additions of organic matter with varying carbon-nitrogen content could be detected using multivariate analysis. The carbonnitrogen content is here used as a proxy for quality, even though it is evident that other chemical components such as phosphorus content and the structure of the organic matter also determine quality. The size of the additions was based on the data of primary production and calculation of export out of the photic zone (Landén \& Hall 1998 and references therein). The highest amount of added carbon corresponds to the input to the sediment during $3 \mathrm{wk}$ of primary production during a typical spring bloom at the studied area. The composition of the organic additions was different mixtures of lignin and Ulva lactuca to create variation in the quality of the organic matter.

\section{MATERIALS AND METHODS}

Sampling and analytical methods. Using a modified USNEL-type box-corer (Blanck et al. 1996), 10 sediment boxes $(0.5 \times 0.5 \times 0.4 \mathrm{~m})$ were collected from $63 \mathrm{~m}$

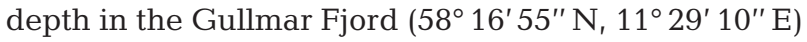
at the end of August 1999 (Fig. 1).

On board the RV 'Arne Tiselius', bottoms and temporary lids were fitted to the boxes of sediment before transportation to Kristineberg Marine Research Station (KMRS), Fiskebäckskil, Sweden. At KMRS, the boxes were immediately placed in a therm-constant room at in situ temperature $\left(6^{\circ} \mathrm{C}\right)$ and particles in the overlying water were allowed to settle for $48 \mathrm{~h}$. During this time the boxes were open and the overlying water was aerated to create slight stirring of the water. A long-term circulation system was then mounted and the boxes were provided with a continuous supply of in situ seawater (Fig. 2), and incubated in the dark, as light penetration to $60 \mathrm{~m}$ depth at the site is limited.

The incoming water was mixed with water already present in the boxcosm through a separate internal circulation creating a laminar flow over the sediment surface. The circulation system and the experimental setup of the boxcosms are described in detail by I. M. Karle (unpubl.). The procedure for the flux measurements in this boxcosm system was as follows: The external in- and outflow was shut off for $8 \mathrm{~h}$. During this time the water remained homogenous through the internal circulation system. On 5 occasions during each flux incubation the water was sampled for oxygen $\left(\mathrm{O}_{2}\right)$, dissolved inorganic carbon (DIC), ammonium $\left(\mathrm{NH}_{4}{ }^{+}\right)$, nitrate and nitrite $\left(\Sigma \mathrm{NO}_{2}{ }^{-}+\mathrm{NO}_{3}{ }^{-}\right)$, and silicate $\left(\Sigma \mathrm{Si}(\mathrm{OH})_{4}\right.$ $\left.+\mathrm{Si}(\mathrm{OH})_{3} \mathrm{O}^{-}\right)$. For simplicity, we will hereafter refer to

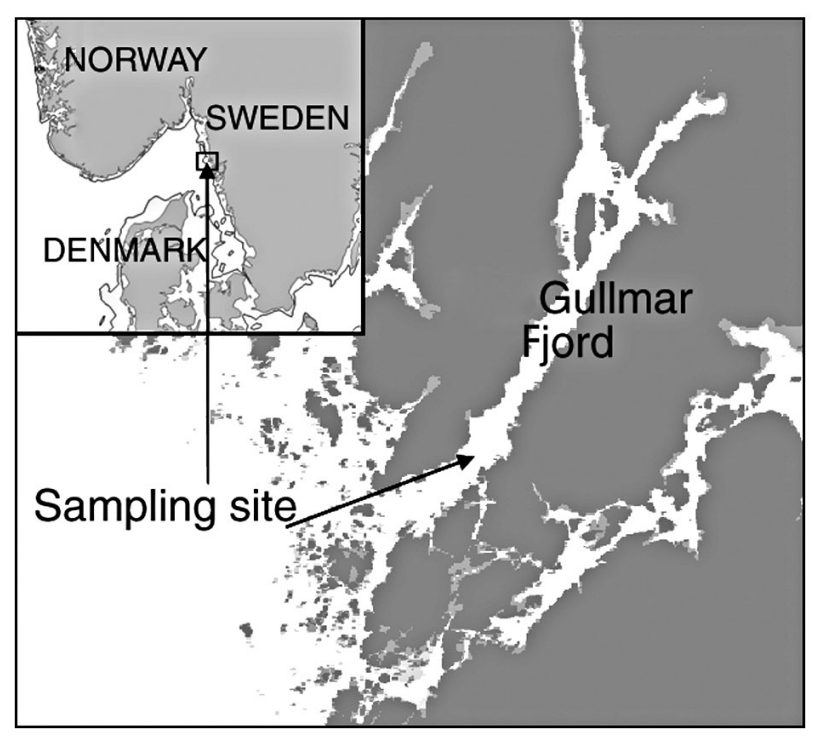

Fig. 1. Sampling site in the Gullmar Fjord (58 $16^{\prime} 55^{\prime \prime} \mathrm{N}$, $11^{\circ} 29^{\prime} 10^{\prime \prime} \mathrm{E}$ ) 


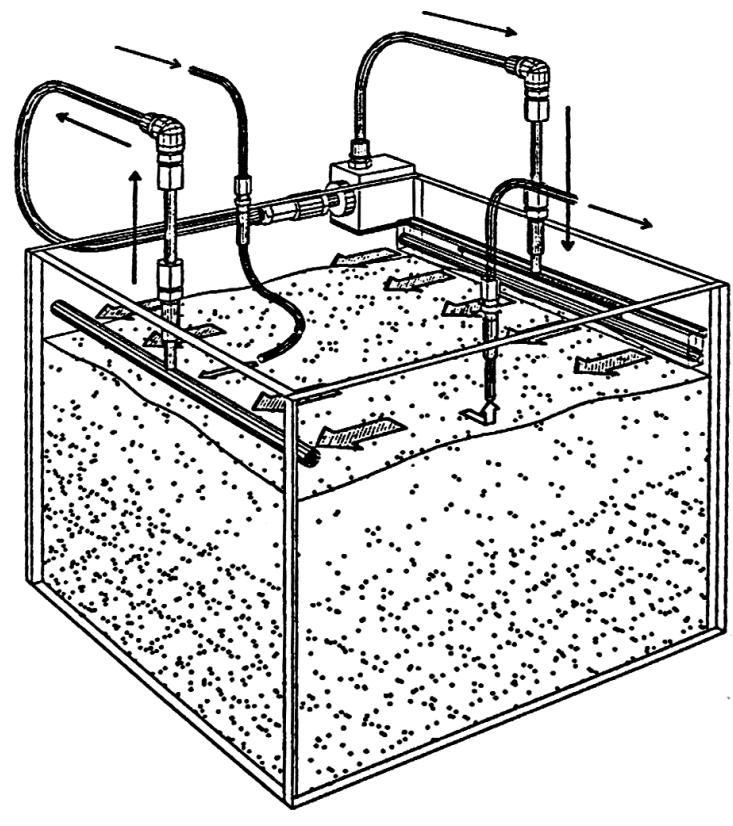

Fig. 2. Boxcosm setup. Internal circulation system perpendicular to incoming water ensures that the water mix remains homogenous

the $\Sigma \mathrm{NO}_{2}{ }^{-}+\mathrm{NO}_{3}{ }^{-}$as $\mathrm{NO}_{3}{ }^{-}$, and $\Sigma \mathrm{Si}(\mathrm{OH})_{4}+\mathrm{Si}(\mathrm{OH})_{3} \mathrm{O}^{-}$as $\mathrm{SiO}_{2}$. Oxygen samples were precipitated according to a modified Winkler technique and stored in the dark for $12 \mathrm{~h}$ at $5^{\circ} \mathrm{C}$ prior to titration. Triplicate DIC samples were gently filtered $(0.20 \mu \mathrm{m})$ and stored for less than $24 \mathrm{~h}$ at $5^{\circ} \mathrm{C}$ prior to analysis on a LICOR LI-6262 (RSD = $<5 \%, \mathrm{n}=3)$. Triplicate nutrient samples were filtered $(0.45 \mu \mathrm{m})$ and immediately analyzed on a Bran+Luebbe TRAACS $800(\mathrm{RSD}=2$ to $5 \%, \mathrm{n}=3)$. All filters were Sartorius cellulose acetate syringe filters rinsed with $50 \mathrm{ml}$ Milli-Q water and flushed with air before use.

Experimental design. Benthic fluxes were measured on 6 occasions over $4 \mathrm{wk}$ (Fig. 3) to cover the natural temporal and spatial heterogeneity of the sediment system. By repeated flux measurements only $2 \mathrm{~d}$ apart, potential carry-over effects from the previous flux measurement could be detected (i.e. pairwise comparison of fluxes from $t=-26$ and $-24 \mathrm{~d}$ versus fluxes from
Table 1. Additions (Boxes A to E) of organic matter to the sediment, including Ulva lactuca (U) and/or freeze-dried, ground lignin (L). All C and $\mathrm{N}$ values in $\mathrm{mmol} \mathrm{m}^{-2}$ except for the C:N ratio, which is dimensionless

\begin{tabular}{|lccccccc|}
\hline Box & $\mathrm{C}_{\mathrm{U}+\mathrm{L}}$ & $\mathrm{N}_{\mathrm{U}+\mathrm{L}}$ & $\mathrm{C}_{\mathrm{U}}$ & $\mathrm{C}_{\mathrm{L}}$ & $\mathrm{N}_{\mathrm{U}}$ & $\mathrm{N}_{\mathrm{L}}$ & $\mathrm{C}_{\mathrm{U}+\mathrm{L}}: \mathrm{N}_{\mathrm{U}+\mathrm{L}}$ \\
\hline $\mathrm{A}$ & 167 & 6.16 & 83.3 & 83.3 & 6.10 & 0.0607 & 27.0 \\
$\mathrm{~B}$ & 41.6 & 0.63 & 8.33 & 33.3 & 0.610 & 0.0243 & 65.6 \\
$\mathrm{C}$ & 291 & 4.44 & 58.3 & 233 & 4.27 & 0.170 & 65.6 \\
$\mathrm{D}$ & 291 & 17.1 & 233 & 58.3 & 17.1 & 0.0425 & 17.0 \\
$\mathrm{E}$ & 41.6 & 2.45 & 33.3 & 8.3 & 2.44 & 0.00607 & 17.0 \\
\hline
\end{tabular}

$t=-19$ and $-17 \mathrm{~d}$ ). The first 6 flux measurements ( $t=-26$ to $-3 \mathrm{~d}$ ) will henceforth be referred to as 'before-fluxes' because they were measured before the addition of organic matter, and the last 6 fluxes $(t=2$ to $40 \mathrm{~d})$ as 'after-fluxes'.

The additions were made according to a full factorial design with 2 factors and 1 centre point (Figs. 4 \& 5) using 'The Unscrambler' v.7.5 software. The first factor was total amount of organic matter $\left(\mathrm{OC}_{\mathrm{tot}}\right)$, the second factor, percentage carbon originating from Ulva lactuca $(\% \mathrm{U})$ representing bioavailable OC and nitrogen.

After the initial 6 flux measurements (Fig. 3), 5 different mixtures of freeze-dried, ground lignin (L) and the green algae Ulva lactuca (U) were added to the sediment (time zero, $t=0$ ). The carbon and nitrogen composition of the additions (A to $E$ ) is summarized in Table 1. Assuming an average mixing depth of $1 \mathrm{~cm}$ during the first $48 \mathrm{~h}$ after addition, the highest additions of carbon content (C and D) increased the total carbon content from 3.00 to $3.11 \%$ sediment dry wt. The corresponding increase for the lowest additions (B and E) was from 3.00 to $3.02 \%$ dry wt. The sediment boxes were designated according to their respective nutrient addition, and the same designation was used to identify the before- and after-fluxes.

Additions were made as a slurry of freeze-dried organic matter and filtered seawater. Using a Pasteur pipette with the tapered point removed, the slurry was added halfway down the water column, evenly spread throughout the water, and allowed to settle for $6 \mathrm{~h}$. Water circulation was then resumed and a further 6 flux measurements were made over a period of $6 \mathrm{wk}$, according to an exponential time schedule (Fig. 3). At the end of the experiment, the sediment was sieved and macrofauna $>2 \mathrm{~cm}$ determined at species level.

Data evaluation. Only fluxes displaying a linear change in concentration over time were used. A 2level full factorial design with 1

\begin{abstract}
centre point was used with additions
\end{abstract}
Fig. 3. Schedule of flux measurements. Fluxes were measured on 6 occasions over a $26 \mathrm{~d}$ time span before addition of organic matter, and on 6 occasions over a $40 \mathrm{~d}$ time span after additions were made 


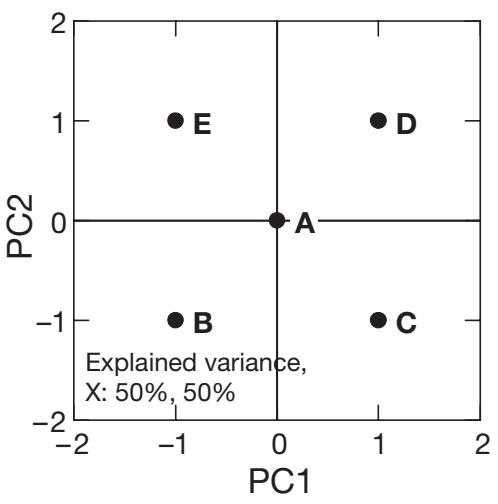

Fig. 4. Principal Component Analysis (PCA) of the additions of organic matter (ground lignin and Ulva lactuca, see Table 1); a projection of the similarities and differences of the additions along 2 principal components (see further details on PCA in 'Materials and methods; Data evaluation'). The explained variance of the first Principal Component (PC1), 50\%, is related to the quantity of added material rather than its composition. Analogously the explained variance in $\mathrm{PC} 2$, $50 \%$, is controlled by the differences in composition (\%U). A: centre point with $2.0 \mathrm{~g} \mathrm{~m}^{-2} \mathrm{OC}_{\text {tot }}$ and $50 \%$ U. lactuca

of organic matter as $x$-variables (Fig. 5) and the flux data as $y$-variables. The complete flux data set was then divided into before- and after-fluxes. The community composition of intact sediment communities cannot be controlled; therefore, each sediment had its own characteristics, resulting in variability in the data that was not related to the additions of organic matter. In order to reduce this variability, the fluxes were normalized to an average 'before-flux' of each solute. The normalized data matrices were then analyzed by Principal Component Analysis (PCA) and Partial Least Square (PLS). To enable equal comparison of the different solute fluxes, the data were weighted with $1 \mathrm{SD}$.

PCA is a multivariate ordination technique; its strength is its ability to extract information and find similarities and differences between samples within large amounts of data. It can also visualize and reveal hidden patterns and relationships that might be difficult to detect in a very complex data matrix. PLS is an extension of PCA, where the PCA of the $\boldsymbol{Y}$-matrix that contains the response variables is fitted through regression analysis to the $\boldsymbol{X}$-matrix that contains the design variables (Fig. 5). The resulting regression equation $(\boldsymbol{Y}=\mathrm{B} 0+\mathrm{B} 1 \boldsymbol{X} 1+\ldots+\mathrm{B} k \boldsymbol{X} k+\boldsymbol{E})$ consist of Bcoefficients that represent the influence of each design variable on the explained variation of the regression model. B0 is the intercept of the regression, and $\boldsymbol{E}$ is an error matrix holding the variance that cannot be explained by the model. The building of the model is made in 2 major steps. Firstly, data calibration is performed, where models are built excluding one calibration point at a time. This is followed by a validation step, where the response variables are excluded. Both steps are tested through simulated prediction of response values that are compared with the measured values within the data set. Both the calibration and validation are evaluated through correlation analysis of

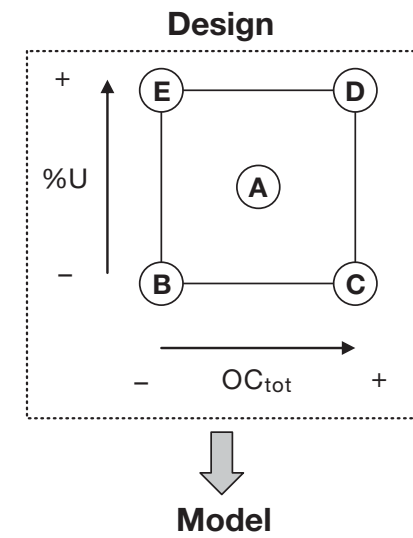

\section{Experimental plan}

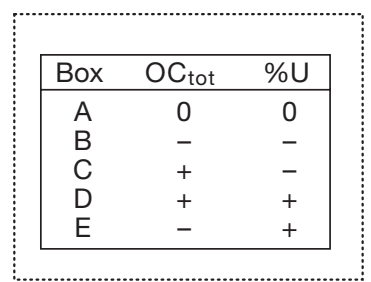

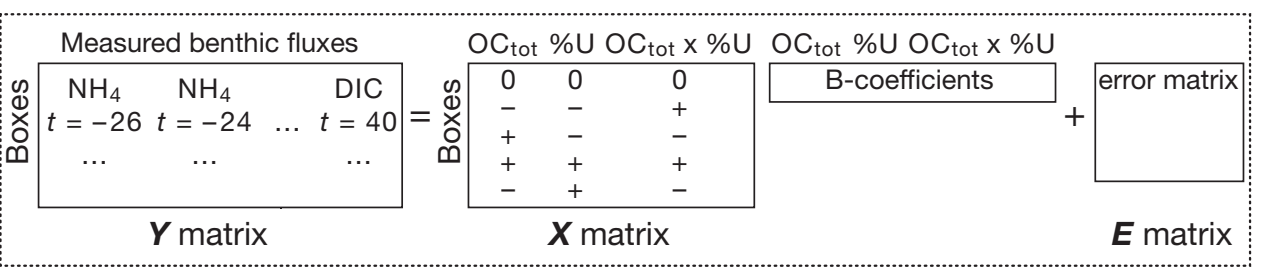

Fig. 5. Experimental design. The 2 factors, amount of total organic carbon $\left(\mathrm{OC}_{\mathrm{tot}}\right)$ and the percentage of Ulva lactuca (\%U) were varied at 2 levels as indicated by the corner circles. One centre point, A, with intermediate levels of both factors was added to investigate potential non-linearity. The regression between the $\boldsymbol{X}$ and $\boldsymbol{Y}$ matrices using the Partial Least Square (PLS)-algorithm results in B-coefficients (regression coefficients) for the 2 main factors, $\mathrm{OC}_{\text {tot }}$ and \% $\mathrm{U}$, as well as for the interaction terms $\mathrm{OC}_{\text {tot }} \times \% \mathrm{U}$. An error matrix $\boldsymbol{E}$ can then be used to predict new flux values from new levels in the $\boldsymbol{X}$ matrix 
predicted and measured response variables. The significance of each response variable was checked for both the calibration and the validation step. However, if the calibration was not statistically significant at a $95 \%$ confidence level, the significance of the validation was also rejected. The specific method PLS2 is suitable when the aim is to simultaneously evaluate effects of the $x$-variables on more than one $y$-variable.

The PLS2 was performed on the afterfluxes at different time scales using all response variables ranging from single flux measurements $(t=2, t=4, \ldots, t=40 \mathrm{~d})$, to the maximum of 6 flux measurements $(t=2$ to $40 \mathrm{~d})$ at the one time. The effect of the additions in terms of which solute(s) that were effected, the duration of the response, and the effect of organic matter composition could thereby be captured. Series of one response variable at the time for the 6 flux measurements were also made (e.g. nitrate, $t=2$ to $40 \mathrm{~d}$ ). Response variables that were significantly affected by the additions were selected for a new PLS2 analysis. The same procedure was also conducted with the before-fluxes data in order to exclude that the results in the after-fluxes data were due to chance. This procedure resulted in 14 PLS analyses, which gave a total of 104 and 112 modelled response variables for beforeand after-fluxes, respectively. The difference in total number of modelled response variables was due to unequal numbers of missing data in respective data set. The percent successfully modelled response variables were compared between the before- and afterfluxes data sets.

The relationship to the addition pattern in Fig. 4 was graphically illustrated in a score plot of the PLS2 result. As the score plot from the PLS2 analysis is based on the regression of the PCAs of the additions and of the measured fluxes, the centre point is fixed at the origin of the coordinates. Therefore, as a final check, a PCA was run on the significant variables given in the PLS2.

\section{RESULTS}

\section{Box specificity of macrofauna composition}

Macrofauna $>2 \mathrm{~cm}$ in the sediments boxes is summarized in Table 2. The most remarkable findings were the presence of hagfish in Boxes C2 and E1 and the large amounts of dead Thyasira sp. shells found at 5 to $10 \mathrm{~cm}$ sediment depth in Box B2.

Box D1, with 11 individuals of Ophiura sarsi in com- bination with the complete absence of any Echinocardium sp., also stood out compared to the other boxes. Other macrofaunal key species not quantitatively determined were the brittlestars Amphiura sp., the polychaetes Heteromastus filiformis, Maldane sarsi, Melinna cristata and Rhodine loveni, and the bivalve Abra nitida.

\section{Flux incubations}

Fluxes of nutrients, oxygen, and DIC were generally linear (Fig. 6). On average, the oxygen concentration decreased between 230 and $210 \mu \mathrm{mol} \mathrm{dm}{ }^{-3}$ during a flux incubation. This moderate decrease in oxygen concentration and the linear changes of the nutrient fluxes during the incubations indicate that the incubations themselves had not affected the results in a statistically significant manner.

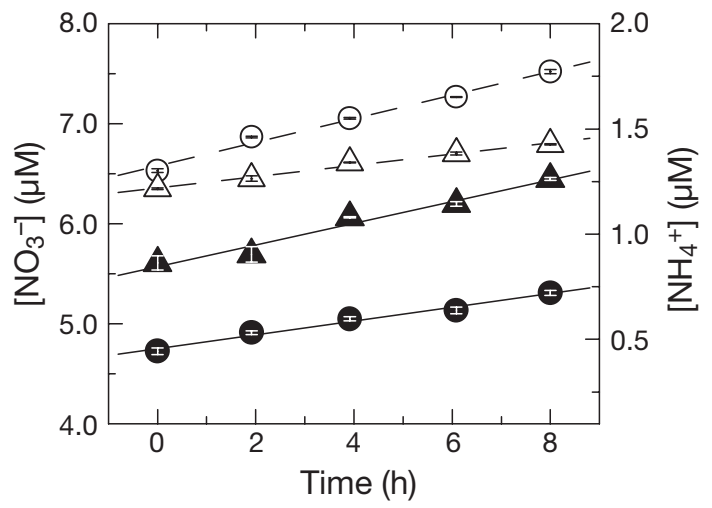

Fig. 6. Increase of ammonium (filled symbols) and nitrate (open symbols) for Box E1 (circles) and Box C2 (triangles) from one sampling occasion ( $t=-2 \mathrm{~d})$. Solid and dashed lines show linear fit $\left(r^{2} \geq 0.97\right)$ to respective series. Error bars indicate \pm SD from triplicate nutrient analysis. Note different scales on the $y$-axes 


\section{Flux development over time}

The complexity of the sediment system was reflected in the variability of the fluxes during the experiment, both before and after addition of organic matter. An example of flux development over time during the experiment is shown in Fig. 7.

The ammonium flux shifted from efflux to influx in all boxes on one or more occasions during the last 3 flux measurements ( $t=16$ to $40 \mathrm{~d}$ ). The beforefluxes data indicated a sampling bias for nitrate and oxygen fluxes (Z-test, $p=0.05)$, resulting in increased nitrate-effluxes and decreased oxygeninfluxes for samples taken only $2 \mathrm{~d}$ apart. This bias affected the fluxes in an opposite direction to the additions; however, the effect of this bias on the magnitude of the responses was small (5 to 10\%) and could therefore be ignored. Fig. 8 details the average fluxes of 2 boxes from each treatment, ranging from $2 \mathrm{~d}$ before until $8 \mathrm{~d}$ after addition. Since the major effect of the addition on the benthic fluxes was apparent within the first $8 \mathrm{~d}$ after addition, Fig. 8 only shows the fluxes from these time points. Due to analytical problems, silicate flux data for the $8 \mathrm{~d}$ is missing.

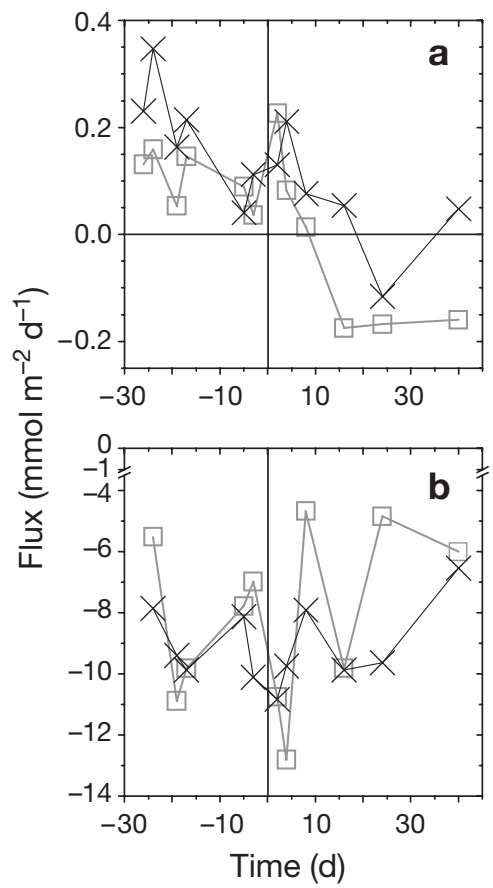

Fig. 7. Flux development of (a) ammonium and (b) oxygen over time in 2 boxes: A1 $(\square)$ and D1 $(\times)$. Vertical lines indicate the day of addition $(t=0)$ of organic matter to the boxes. Note different scales on the $y$-axes
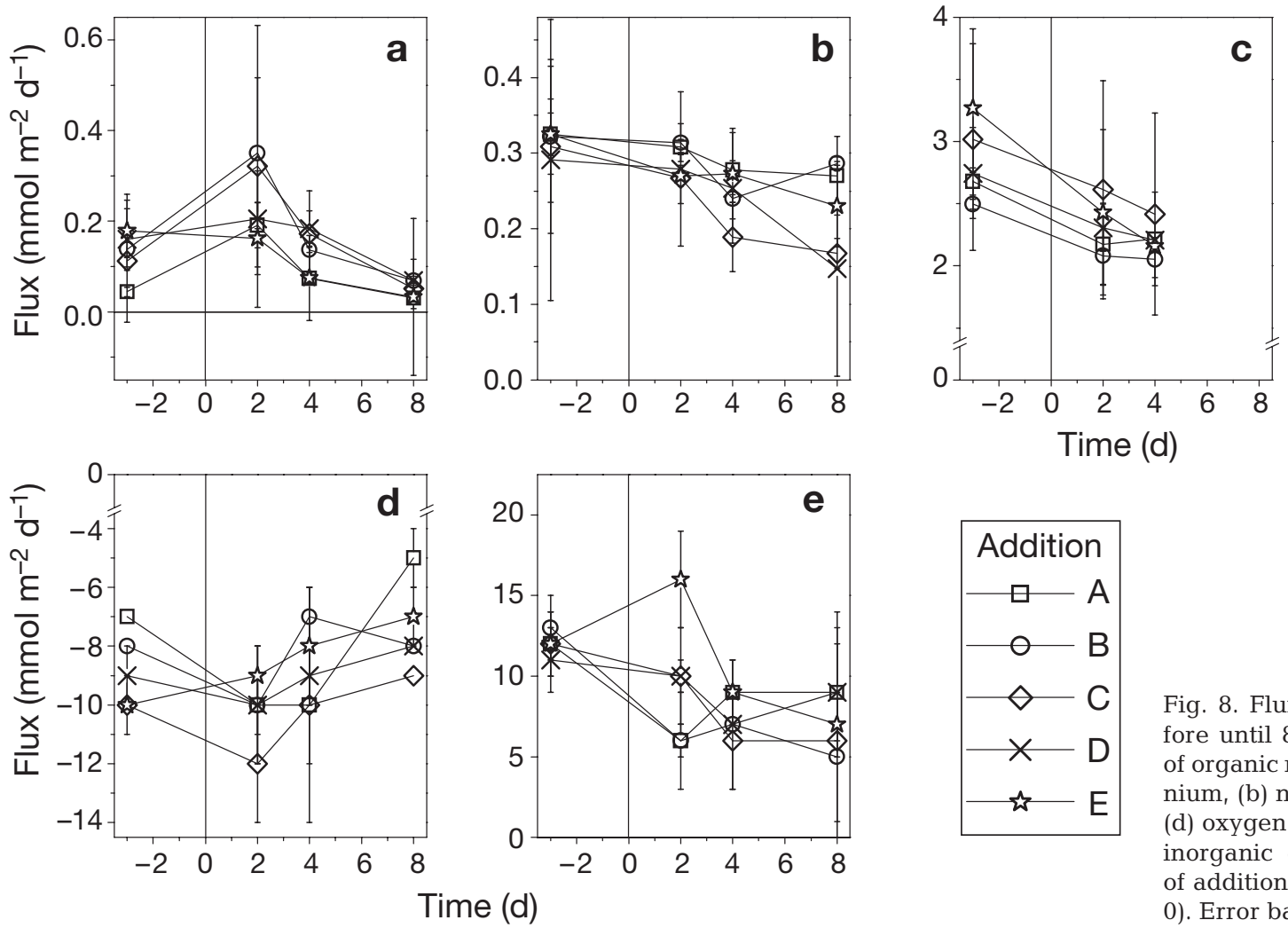

Fig. 8. Fluxes from $2 \mathrm{~d}$ before until $8 \mathrm{~d}$ after addition of organic matter: (a) ammonium, (b) nitrate, (c) silicate, (d) oxygen and (e) dissolved inorganic carbon. The day of addition is set to zero $(t=$ $0)$. Error bars: $\pm 1 \mathrm{SD}(\mathrm{n}=2)$ 
Fig. 9. (a-d) PLS2 score plots (on the same scale) for before and after fluxes. Note the fixed central position of the centre point A. The most significant scores: (a) before-fluxes, $t=-26$ to $-3 \mathrm{~d}$ i (b) after-fluxes, $t=2$ to $40 \mathrm{~d}_{\text {; }}$ (c) after-fluxes, $t=2$ to $8 \mathrm{~d}$; (d) significant response variables originating from the PLS2 $(t=2$ to $8 \mathrm{~d})$. The regression coefficient, $\mathrm{R}^{2}$, and the significance, $\mathrm{p}$, of the predicted versus measured values for respective response variable in the PLS2 analysis are given. Note that $\mathrm{NH}_{4} t=4 \mathrm{~d}$ and $\mathrm{SiO}_{2} t=4 \mathrm{~d}$ both had a significant calibration but failed in the validation step. (e) PCA score plot of the same significant variables used in (d). Note that A is not fixed in the origin of coordinates and that the measured fluxes constitute the $x$-variables in a PCA
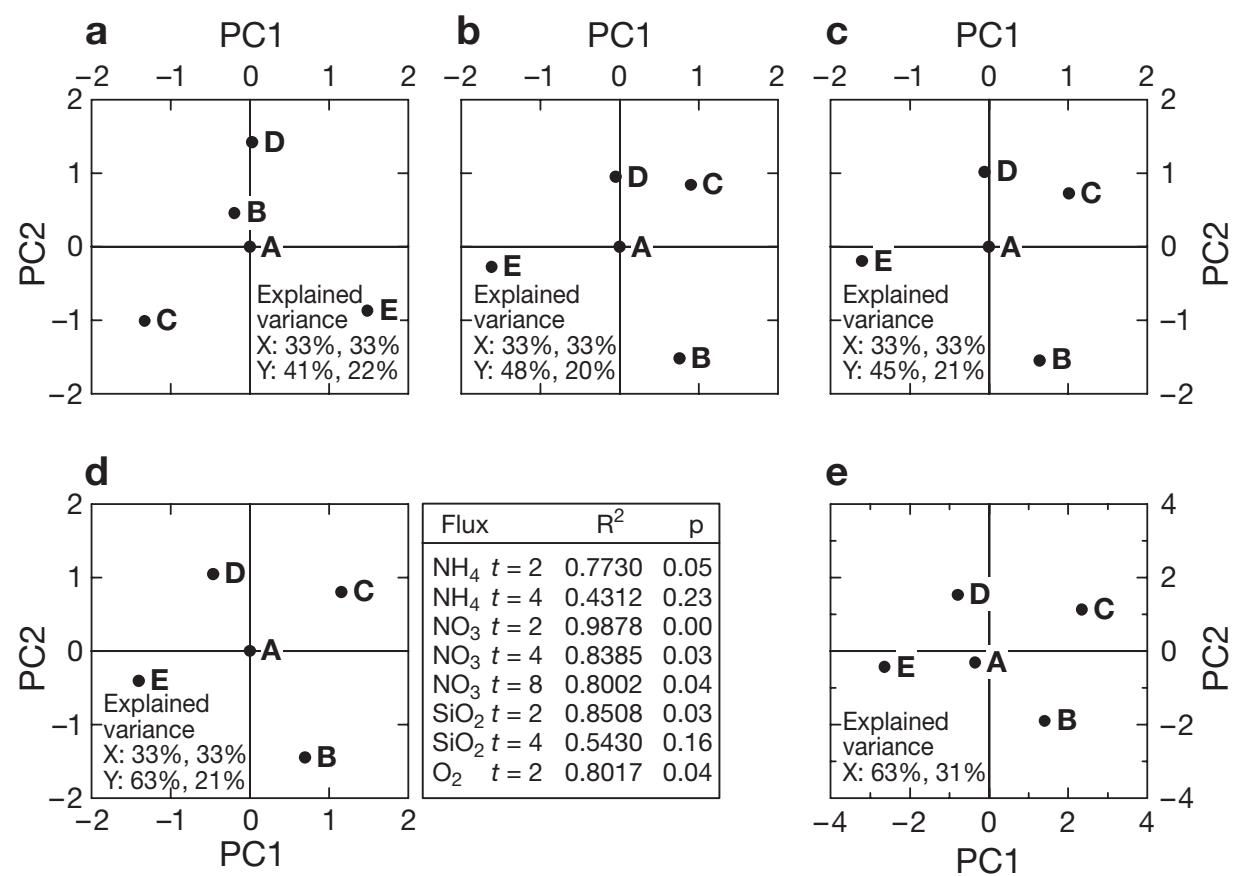

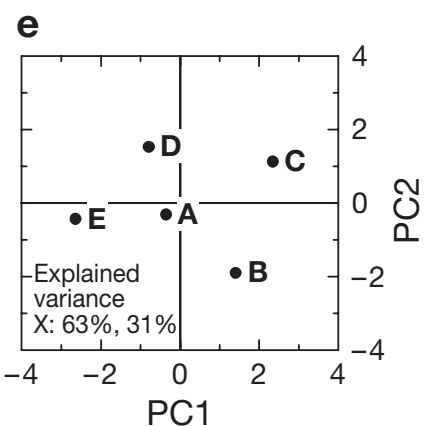

\section{Effects of additions of organic matter-evaluation using PLS2}

Flux analysis

Variation in fluxes between some replicate boxes (e.g. C1 and C2, data not shown) became larger after addition because of the box specificity due to fauna composition. The PLS2 analysis of the individual 10 replicate boxes was therefore not able to distinguish a pattern related to the addition, so instead the average of the 2 boxes from each respective treatment was used.

The PLS2 analyses of the before-fluxes data set resulted in 5 significant modelled response variables out of a possible 104, which equals $4.8 \%$ (Fig. 9a). In comparison, the analysis of the after-fluxes data produced 34 significant modelled response variables out of a possible 112 (30\%), all with higher significant validation than the 5 resulting from the before-fluxes data. The PLS2 score-plot of the complete after-fluxes data set showed likeness to the PCA for the experimental addition pattern, as confirmed by the significant models in the PLS2 analysis (Fig. 9b-d). Two principal components were sufficient to explain $68 \%$ of the total variation of the $\boldsymbol{Y}$-variables, where the first principal component explained $48 \%$ and the second $20 \%$ (Fig. 9b). The clearly most significant regression in a PLS2 was the analysis of time series $t=2$ to $8 \mathrm{~d}$ for all solutes (Fig. 9c-e). In the PLS2 analysis of fluxes of all solutes $t=2$ to $8 \mathrm{~d}$, there were 6 specific fluxes showing a significant regression between predicted versus measured flux, including ammonium, nitrate, silicate and oxygen $2 \mathrm{~d}$ after addition, and nitrate fluxes up to $8 \mathrm{~d}$ after addition. The fluxes of ammonium, silicate and oxygen 4 to $8 \mathrm{~d}$ after addition, together with all the DIC fluxes could not be used for significant simulated prediction of fluxes in the model. Using the fluxes that showed a significant regression between a predicted versus measured flux in the PLS2, a PCA using these fluxes, confirmed the pattern resemblance of the additions (Fig. 9e).

\section{B-coefficients}

The B-coefficients show which response variables were affected by the different parameters in the additions; $\mathrm{OC}_{\text {tot, }}$ and the quality of organic matter (expressed as \%U), and the interaction between the 2 factors $\left(\mathrm{OC}_{\text {tot }} \times \% \mathrm{U}\right.$ ) (Fig. 10). These B-coefficients are also used when predicting effects of additions other than those made in the experiment. As all variables contribute to the specific model of the fluxes for all solutes $(t=2$ to $8 \mathrm{~d})$ all B-coefficients from the model are evaluated below, even though only 6 of them were able to predict measured fluxes with $95 \%$ significance.

Ammonium fluxes. All ammonium fluxes during the first $8 \mathrm{~d}$ after addition were effluxes. Initially \%U had the highest influence on the ammonium flux $(t=2 \mathrm{~d}$, $B=-0.85)$, resulting in a decreased efflux. $\% U$ declined to less than half $8 \mathrm{~d}$ after the addition $(t=8 \mathrm{~d}, \mathrm{~B}=$ -0.36). $O C_{\text {tot }}$ gave, on the other hand, an increased efflux, most pronounced $4 \mathrm{~d}$ after addition, where the relative importance of the total amount $(B=10.69 \mid)$ was 


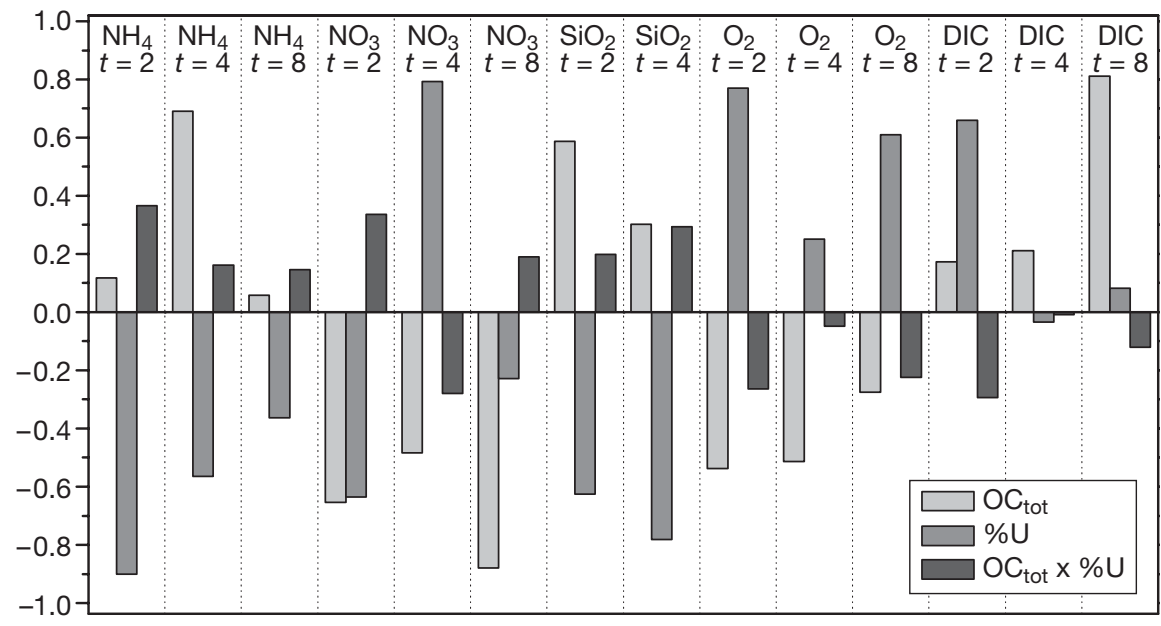

Fig. 10. B-coefficients from the PLS2 analysis of the 3 first fluxes after addition ( $t=2$ to $8 \mathrm{~d}$ ). All measured fluxes are effluxes except for oxygen, which is constantly consumed in the sediment creating an influx. Consequently a negative value of a B-coefficient means a decreased efflux, while a positive B-coefficient means an increased efflux for fluxes of all solutes except for oxygen. For oxygen, a negative B-coefficient results in an increased influx and correspondingly a positive B-coefficient results in a decreased influx larger compared to the quality ( $\% U, B=|0.56|)$. The interaction between quality and quantity $\left(\mathrm{OC}_{\text {tot }} \times \% \mathrm{U}\right)$ increased the ammonium fluxes to a larger extent than the total organic matter at 2 and $8 d$, but was always less important than the quality.

Nitrate fluxes. The nitrate fluxes during the first $8 \mathrm{~d}$ after addition were also effluxes. Two days after addition, quality and quantity had an equal influence on the flux ( $\% \mathrm{U}$ and $\mathrm{OC}_{\text {tot, }} \mathrm{B} \sim 10.65 \mathrm{I}$ ), while the magnitude of the interaction was approximately half the size $\left(\mathrm{OC}_{\mathrm{tot}} \times\right.$ $\% \mathrm{U}, \mathrm{B}=\mid 0.34 \mathrm{I})$. The quality of organic matter affected the nitrate fluxes through decreased effluxes at 2 and $8 \mathrm{~d}$ in the same manner as for the ammonium fluxes. However, $4 \mathrm{~d}$ after addition the quality of organic matter gave rise to increased efflux of nitrate, which was larger than the effect of total amount of organic matter and the interaction put together $(\% \mathrm{U}, \mathrm{B}=10.79)_{\text {; }} \mathrm{OC}_{\text {tot }}$, $\left.\mathrm{B}=10.48 \mathrm{I} ; \mathrm{OC}_{\mathrm{tot}} \times \% \mathrm{U}, \mathrm{B}=10.28 \mathrm{I}\right)$. Contrary to the influence on ammonium fluxes, $\mathrm{OC}_{\text {tot }}$ decreased nitrate effluxes at all time points. The influence of quantity was most pronounced after $8 \mathrm{~d}\left(\mathrm{OC}_{\text {tot }}, \mathrm{B}=-0.88\right)$, when quality had become less important and of the same order as the interaction factor ( $\% \mathrm{U}, \mathrm{B}=-0.23)$.

Silicate fluxes. All silicate fluxes during the first $4 \mathrm{~d}$ after addition were effluxes. Two days after addition, the influence of quality of organic matter created a decreased efflux of approximately the same magnitude as total organic matter caused an increased efflux $\left(\mathrm{U} \%, \mathrm{~B} 0=10.63\left|; \mathrm{OC}_{\text {tot }} \mathrm{B}=\right| 0.59 \mid\right)$. The influence of the interaction between quality and quantity $\left(\mathrm{OC}_{\text {tot }} \times \% \mathrm{U}\right)$ increased from 0.20 to 0.29 between 2 and $4 \mathrm{~d}$ after addition, and on Day 4 it had almost the same influence as $\mathrm{OC}_{\text {tot }}(\mathrm{B}=0.30)$. As the influence of organic matter $\left(\mathrm{OC}_{\text {tot }}\right)$ gave less enhanced effluxes over time, the quality caused decreased effluxes over time ( $\mathrm{B}=$ -0.63 to -0.78 over $4 \mathrm{~d}$ ).

Oxygen fluxes. All oxygen fluxes during the first $8 \mathrm{~d}$ after addition were influxes. The oxygen fluxes con- stantly decreased due to \% $\mathrm{U}$, and increased due to $\mathrm{OC}_{\text {tot }}$ and $\mathrm{OC}_{\text {tot }} \times \% U$, whereas the influence of quality initially dominated $(\% \mathrm{U}, \mathrm{B}=10.77 \mathrm{l})$. This pattern was the same throughout the $8 \mathrm{~d}$, although the relative importance of the factors varied. Four days after the addition, the influence of total amount of organic matter remained the same at $B=|0.51|$, whereas the relative influence of quality and the interaction were less than that of total amount of carbon. On Day 8 after the addition, the relative influence of the factors was the same as initially, but with lower B-coefficients for all factors.

DIC fluxes. All DIC fluxes during the first $8 \mathrm{~d}$ after addition were effluxes. Both the quality and quantity of organic matter resulted in an increased DIC efflux ( $\left.\% \mathrm{U}, \mathrm{B}=0.66 ; \mathrm{OC}_{\text {tot }}, \mathrm{B}=0.2\right)$, whereas the interaction resulted in a decreased efflux $(\mathrm{B}=-0.3)$. $\mathrm{OC}_{\text {tot }}$ got stronger over the $9 \mathrm{~d}$, as the $\% \mathrm{U}$ and $\mathrm{OC}_{\text {tot }} \times \% \mathrm{U}$ was reduced.

\section{DISCUSSION}

Although the additions of organic matter to intact, naturally heterogeneous sediment boxes were small but ecologically relevant, our experiment provided information on the relative importance of quantity and quality of the additions. Two days after addition, \%U had a greater influence on the benthic fluxes than $\mathrm{OC}_{\text {tot }}$. Later the pattern changes, and $8 \mathrm{~d}$ after addition $\mathrm{OC}_{\text {tot }}$ was more important for the response of the benthic fluxes. The addition of organic matter varied between 0.5 and $3.5 \mathrm{~g}$ $\mathrm{m}^{-2}$, and the quality varied between 0.2 and $0.8 \mathrm{~g} \mathrm{~m}^{-2}$, which leads to the interpretation below.

An addition of a small quantity with high quality organic matter (Addition E), resulting in a low $C: N$ ratio, was the only treatment that initially gave a decreased efflux of ammonium. In contrast, for Addi- 
tion $\mathrm{D}$, which had a 7 -fold larger carbon addition but the same $\mathrm{C}$ : $\mathrm{N}$ ratio as Addition $\mathrm{E}$, the ammonium efflux was increased. Likewise, Addition B, which had the same amount of organic matter as Addition E, but a higher $\mathrm{C}: \mathrm{N}$ ratio, also resulted in an increased efflux. This suggests that as long as the quantity and quality of the addition matches the potential activity of the microbial community present at the time, the organic matter will be sequestered without losses to the water column. Therefore, the enhanced ammonium efflux resulting from Additions A to D can to a large extent be explained by the sudden introduction of either too much organic matter containing both ammonium and nitrate from potential intracellular storage in Ulva lactuca (Rosenberg \& Ramus 1982, Lundberg et al. 1989), or organic matter with a too high $\mathrm{C}: \mathrm{N}$ ratio to readily be incorporated in the microbial biomass. These results are in line with previous results from simplified smallscale experiments with additions of organic matter to sieved sediment from the same site (Dahllöf \& Karle 2005). The results from the latter study suggested that an addition of organic matter with a low C:N ratio will have a larger impact on sustaining eutrophication via increased ammonium effluxes, than organic matter with high $\mathrm{C}: \mathrm{N}$ ratio when the same amount of carbon is added. These results paralleled the response predicted by our model for Additions $\mathrm{C}$ and D (3.5 $\mathrm{mg} \mathrm{m}^{-2}$; C:N ratio 66 and 17, respectively), which predicted excess ammonium fluxes of 13 and $30 \mu \mathrm{mol} \mathrm{m} \mathrm{m}^{-2}$, respectively. Again, this indicates that the potential activity of the microbial community to sequester organic matter is important, probably because the microbial assimilation is slower compared to the extracellular hydrolytic activity (Arnosti 2004, Weston et al. 2006 and references therein). Therefore, in the case of Additions E and $\mathrm{B}$, which contained a smaller amount of organic matter $\left(0.5 \mathrm{mg} \mathrm{m}^{-2}\right)$ than the other treatments, the additions decreased the ammonium efflux, suggesting that the assimilation capacity of the microbial community was sufficient to handle this amount of organic matter. As the decrease in ammonium flux was larger for Addition $\mathrm{E}$ than $\mathrm{B}\left(-57\right.$ and $-14 \mu \mathrm{mol} \mathrm{m} \mathrm{m}^{-2} \mathrm{~d}^{-1}$, respectively) it seems likely that the microbial assimilation capacity was even larger than the addition given. Interpolating the model for ammonium fluxes at this initial stage $(t=2 \mathrm{~d})$, shows that assimilation capacity would be reached at $2.5 \mathrm{mg} \mathrm{m}^{-2}$ added organic matter irrespective of the quality. This prediction, however, is only valid for the 2 types of quality used in this study (lignin and Ulva lactuca). As pointed out by both Arnosti \& Holmer (2003) and Bühring et al. (2006), organic matter additions of different quantities but with same quality, as well as equal quantities of different qualities, give different responses from the microbial community: not only the $C: N$ ratios are of importance to the response, but also other nutrient components such as phosphorus, as well as the structure of the organic matter and the composition of the microbial communities.

The multivariate analysis reveals that both the quality and quantity of the additions produced decreased nitrate effluxes $2 \mathrm{~d}$ after addition, suggesting enhanced removal of $\mathrm{N}$ by anaerobic processes such as denitrification and anammox before response of the nitrifying microorganisms. The increased availability of ammonium would trigger growth of the autotrophic nitrifying microbial community only slowly, whereas the denitrifying organisms were probably already stimulated by nitrate present in the organic matter, contributing to the net decrease of nitrate effluxes for all treatments. Further support for this scenario was found $4 \mathrm{~d}$ after addition, where the quality (\%U) gave an increased nitrate efflux, which indicates that the ammonium content of the material induced nitrification after a lag time. Carbon content did not induce nitrification activity. Strauss \& Lamberti (2000) explained reduced nitrification due to carbon additions (to freshwater sediment) as enhanced competition between the dissimilative use of ammonium as electron donor by nitrifiers and assimilation of ammonium for growth by heterotrophic bacteria. The heterotrophs thereby outcompeted the nitrifiers when the system changed from carbon to nitrogen limitation from the heterotrophs' perspective, which fits well with our data. However, in the case of additions of both high quality and large quantity, there is still a delay in the nitrifiers' response to addition. This delay can be explained by the slow growth of nitrifying bacteria (Madigan et al. 1997), a result of their dissimilative use of ammonium or nitrite as electron donor. Oxidation of ammonium and nitrite are not very efficient energy sources as they have relatively high reduction potentials. This suggests that despite increased ammonium concentration, nitrification will not be enhanced until there is significantly increased growth of the nitrifying community. The effect of the addition could be seen during all $40 \mathrm{~d}$ of the experiment, but it was only within the first $8 \mathrm{~d}$ that significant predictions could be made. The analysis of individual time points (2, 4 and $8 \mathrm{~d}$ after addition) showed a too high resolution to describe the response, indicating that the response has to be measured at more than one time point, in order to achieve a suitable grain and extent of the temporal scale (Petersen et al. 2003). The time series analysis (40 d span) of single solute fluxes (e.g all nitrate fluxes after addition) could not be used for predictive purposes, which most likely is due to the coupled reaction, where the different solutes are linked to one another, a relationship which then is not reflected if only one solute is analyzed on its own. 
The variables that were significantly validated can be used for predictions of flux responses to other combinations of quality and quantity than those used in the design. However, the variables that were significant also for prediction were limited to the first sampling after addition for all solute fluxes except DIC, but for nitrate the effect continued at least for another $6 \mathrm{~d}$. The insignificant effect for the silicate fluxes 4 to $8 \mathrm{~d}$ after addition is probably due to background activities controlling the fluxes, as the major process affecting silicate fluxes at this type of environment in the Gullmar Fjord is bioirrigation (Rutgers van der Loeff et al. 1984). Hence, after the initial stimulation of faunal activity, the silicate flux cannot be expected to be significantly related to the addition, but rather to the faunal composition of each individual box. Likewise, background aerobic respiration, producing DIC, will probably overshadow the effect of the additions at any other time than immediately after addition. The background fluxes of oxygen or DIC are in absolute numbers approximately 2 orders of magnitude larger than nitrogen fluxes, which is why the nitrogen fluxes will potentially be more affected than the oxygen or DIC fluxes. For ammonium, the case of later insignificant ammonium fluxes can be explained by the rapid turnover of ammonium, either as incorporation into biomass or as electron donor for nitrifying bacteria. However, even though the predictable response of the additions was limited to a short timescale after addition, it is still remarkable that the effects of such small additions to intact sediment could be detected and related to their quality and quantity.

The skewness of the picture of the addition pattern reconstructed in the PCA (Fig. 9e) is most likely due to faunal effects that were too big to be handled by our box specificity approach. The differences in faunal composition of the 10 boxes will also naturally be reflected in their response to the additions of organic matter. Depending on what functional groups are represented, e.g. compare Box D1, lacking the bulldozing heart urchins, with Box B1 with a total of 8 heart urchins, differences in the benthic fluxes can be expected. For example, the response of the hagfish in Box C2 to the organic matter addition might overshadow the other effects of the additions, resulting in a more different flux pattern in Box C1 compared to Box $\mathrm{C} 2$ after addition. This brings up the issue of the representative size of the incubations. If one box is inhabited by, on average, larger organisms than another, it might be a problem that the ecological relevance is lesser for the first box. In classic experimental design, it is well known that it is difficult to work with intact sediment communities, and that there is always a trade-off between: (1) the degree of control of the experiment; (2) the ecological relevance; and (3) having enough replication to ensure generality of the results (Schindler 1998, Petersen et al. 2003, Srivastava et al. 2004). Previous studies (Dahllöf et al. 1999, 2001) have suggested that 3 to 4 boxes were enough to cover the spatial variation of the sampled site in the Gullmar Fjord (Fig. 1). As multivariate replication works differently than replication in classic experimental design by a more efficient use of replication in the entire design, we found it reasonable to use only duplicate boxes in this experiment. In the future one might consider increasing the number of replicates, at least in some points of the design.

\section{CONCLUSIONS}

Two to $8 \mathrm{~d}$ after addition was the most suitable scale for studying the effect of ecologically relevant additions of organic matter in the studied coastal sediment. The multivariate regression model of the response showed significant predictions of simulated measured fluxes of ammonium, oxygen, and silicate $2 \mathrm{~d}$ after addition, and for nitrate 2 to $4 \mathrm{~d}$ after addition. In order to use the obtained model for predictive analysis, its validity needs to be further tested; but the results suggest that the use of benthic fluxes as response variables to organic matter enrichment in multivariate designed and evaluated experiments could be a useful tool for characterization of areas of potential risk of eutrophication. In case of further development of the model, potential variables to include could be physical and chemical parameters for different locality characteristics of the benthic community, as well as more levels of organic matter addition in order to increase the generality of the model.

Acknowledgements. We thank the staff at Kristineberg Marine Research Station for skilful help. This study was supported financially by the Swedish Research Council (VR) and Göteborg University Marine Research Center.

\section{LITERATURE CITED}

Aller RC, Benninger LK (1981) Spatial and temporal patterns of dissolved ammonium, manganese, and silica fluxes from bottom sediments in Long Island Sound. J Mar Res 39:295-314

Arnosti C (2004) Speed bumps and barricades in the carbon cycle: substrate structural effects on carbon cycling. Mar Chem 92:263-273

Arnosti C, Holmer M (2003) Carbon cycling in a continental margin sediment: contrasts between organic matter characteristics and remineralization rates and pathways. Estuar Coast Shelf Sci 58:197-208

Bianchi TS, Johansson B, Elmgren R (2000) Breakdown of phytoplankton pigments in Baltic sediments: effects of anoxia and loss of deposit-feeding macrofauna. J Exp Mar Biol Ecol 251:161-183 
Blanck H, Hall P, Molander S, Dahllöf I, Magnusson K, Agrenius S (1996) Ecotoxicological effects on biogeochemical processes in marine sediments. Report to the Swedish National Environmental Agency. Göteborg University and Chalmers University of Technology, Gothenburg

Bühring SI, Lampadariou N, Moodley L, Tselepides A, Witte U (2006) Benthic microbial and whole-community responses to different amounts of ${ }^{13} \mathrm{C}$-enriched algae: in situ experiments in the deep Cretan Sea (Eastern Mediterranean). Limnol Oceanogr 51:157-165

Dahllöf I, Karle IM (2005) Effect on marine sediment nitrogen fluxes caused by organic matter enrichment with varying organic carbon structure and nitrogen content. Mar Chem 94(1-4):17-26

Dahllöf I, Blanck H, Hall P, Molander S (1999) Long-term effects of tri-n-butyl-tin on the function of a sediment community. Marine Ecol Prog Ser 18:1-11

Dahllöf I, Agrenius S, Blanck H, Hall P, Magnusson K, Molander S (2001) The effect of TBT on the structure of a marine sediment community: a boxcosm study. Mar Pollut Bull 42(8):689-695

Enoksson V (1993) Nutrient recycling by coastal sediments: effects of added algal material. Mar Ecol Prog Ser 92: 245-254

Enoksson V, Rudén-Berg L (1983) A system for determining exchanges between sediment and water exemplified by nitrogen flux under controlled oxygen conditions. Environ Biogeochem 35:243-250

Galloway JN, Dentener FJ, Capone DG, Boyer EW and 11 others (2004) Nitrogen cycles: past, present, and future. Biogeochemistry 70:153-226

Grall J, Chauvaud L (2002) Marine eutrophication and benthos: the need for new approaches and concepts. Glob Change Biol 8:813-830

Gray JS, Wu RSS, Or YY (2002) Effects of hypoxia and organic enrichment on the coastal marine environment. Mar Ecol Prog Ser 238:249-279

Hansen LS, Blackburn TH (1991) Aerobic and anaerobic mineralisation of organic material in marine sediment microcosms. Mar Ecol Prog Ser 75:283-291

Hylland K, Skold M, Gunnarsson JS, Skei J (1996) Interactions between eutrophication and contaminants. IV. Effects on sediment-dwelling organisms. Mar Pollut Bull 33:90-99

Landén A, Hall POJ (1998) Seasonal variation of dissolved and adsorbed amino acids and ammonium in a near-shore marine sediment. Mar Ecol Prog Ser 170:67-84

Lundberg P, Weich RG, Jensén P, Vogel HJ (1989) Phosphorus-31 and nitrogen-14 NMR studies of the uptake of phosphorus and nitrogen compounds in the marine macroalgae ulva lactuca. Plant Physiol 89:1380-1387

Madigan MT, Martinko JM, Parker J (1997) Brock biology of microorganisms, 8th edn. Prentice-Hall International, London

Morgan E (1991) Chemometrics: experimental design. John Wiley \& Sons, London

Editorial responsibility: Howard Browman (Associate Editorin-Chief), Storebø, Norway
Nixon SW (1995) Coastal marine eutrophication: a definition, social causes, and future concerns. Ophelia 41:199-219

Pearson TH, Rosenberg R (1978) Macrobenthic succession in relation to organic enrichment and pollution of the marine environment. Oceanogr Mar Biol Annu Rev 16:229-311

Pedersen AGU, Berntsen J, Lomstein BA (1999) The effect of eelgrass decomposition on sediment carbon and nitrogen cycling: a controlled laboratory experiment. Limnol Oceanogr 44:1978-1992

Petersen JE, Kemp WM, Bartleson R, Boynton WR and 12 others (2003) Multi-scale experiments in coastal ecology: improving realism and advancing theory. Bioscience 53: 1181-1197

Rosenberg C, Ramus J (1982) Ecological growth strategies in the seaweeds Gracilaria foliifera (Rhodophyceae) and Ulva sp. (Chlorophyceae): soluble nitrogen and reserve carbohydrates. Mar Biol 66:251-259

Rosenberg R, Nilsson HC (2005) Deterioration of soft-bottom benthos along the Swedish Skagerrak coast. J Sea Res 54: 231-242

Rutgers van der Loeff MM, Anderson LG, Hall POJ, Josefson AB, Sundby B, Westerlund SFG (1984) The asphyxiation technique: an approach to distinguish between molecular diffusion and biological mediated transport at the sediment-water interface. Limnol Oceanogr 29:675-686

Schindler DW (1998) Replication versus realism: the need for ecosystem-scale experiments. Ecosystems 1:323-334

Sloth NP, Blackburn H, Hansen LS, Risgaardpetersen N, Lomstein BA (1995) Nitrogen cycling in sediments with different organic loading. Mar Ecol Prog Ser 116:163-170

Srivastava DS, Kolasa J, Bengtsson J, Gonzalez A and 6 others (2004) Are natural microcosms useful model systems for ecology? Trends Ecol Evol 19:379-384

Strauss EA, Lamberti GA (2000) Regulation of nitrification in aquatic sediments by organic carbon. Limnol Oceanogr 45:1854-1859

Sundby B, Anderson LG, Hall POJ, Iverfeldt $\AA$, Rutgers van der Loeff MM, Westerlund SFG (1986) The effect of oxygen on release and uptake of cobalt, manganese, iron and phosphate at the sediment-water interface. Geochim Cosmochim Acta 50:1281-1288

Van Duyl FC, Kop AJ, Kok A, Sandee AJJ (1992) The impact of organic matter and macrozoobenthos on bacterial and oxygen variables in marine sediment boxcosms. Neth $\mathrm{J}$ Sea Res 29:343-355

Weston NB, Porubsky WP, Samarkin VA, Erickson M, Macavoy SE, Joye SB (2006) Porewater stoichiometry of terminal metabolic products, sulfate, and dissolved organic carbon and nitrogen in estuarine intertidal creek-bank sediments. Biogeochemistry 77:375-408

Wold S (1995) Chemometrics: what do we mean with it, and what do we want from it? Chemom Intell Lab Syst 30: 109-115

Wulff F, Rahm L, Hallin AK, Sandberg J (2001) A nutrient budget model of the Baltic Sea. Springer-Verlag, Berlin

Submitted: July 12, 2006; Accepted: December 6, 2006

Proofs received from author(s): July 11, 2007 